\title{
The prevalence and predictors of tuberculin positivity in subjects screened for reasons other than contact investigation
}

\author{
Eduardo Hernández-Garduño MD MHSc, R Kevin Elwood MD FRCPC
}

E Hernández-Garduño, RK Elwood. The prevalence and predictors of tuberculin positivity in subjects screened for reasons other than contact investigation. Can Respir J $2008 ; 15(4): 181-187$.

BACKGROUND: No previous studies have estimated the rates of tuberculin positivity (TP) in noncontact populations within the same community, which is important for prioritizing and implementing preventive measures.

OBJECTIVES: To estimate the prevalence and predictors of TP in noncontact populations.

METHODS: A retrospective analysis of tuberculin results of noncontact populations screened in British Columbia from 1990 to 2002 was conducted.

RESULTS: The period prevalence of TP in 59,791 screened subjects was $12.7 \%$ (95\% CI $12.4 \%$ to $13.0 \%$ ), $30.4 \%$ (95\% CI $28.2 \%$ to $32.7 \%$ ) and $60.9 \%$ (95\% CI $60.3 \%$ to $61.6 \%$ ) for Canadian-born non-Aboriginals (CBNAs), Canadian-born Aboriginals (CBAs) and foreign born (FB), respectively. After controlling for age and sex, independent predictors of TP included Bacille Calmette-Guérin (BCG) vaccination (OR 19.6, 95\% CI 17.9 to 21.5 ), country of birth (CBA: OR 2.87, 95\% CI 2.44 to 3.37; FB: OR 3.67, 95\% CI 3.34 to 4.03 ) and the following populations: correctional centre residents (OR 4.14, 95\% CI 1.87 to 9.15), residents of long-term care and community care facilities (OR $1.79,95 \%$ CI 1.44 to 2.23), immigrants (OR 1.75, $95 \%$ CI 1.50 to 2.04), health centre employees (OR 1.71, $95 \%$ CI 1.56 to 1.88 ), volunteers (OR 1.38 , 95\% CI 1.14 to 1.68 ), self-referred healthy subjects (OR 1.30, 95\% CI 1.15 to 1.48 ) and students (OR 1.27, 95\% CI 1.19 to 1.35). CBAs, FB and male subjects were less likely to react to tuberculin than CBNAs and female subjects among those vaccinated with Bacille Calmette-Guérin $(\mathrm{P}<0.05)$.

CONCLUSIONS: Rates of TP correlate with disease rates by sex and origin. The continuation of tuberculin screening programs is warranted in noncontact populations with high TP rates, where unknown exposure to active cases is more likely to occur. Further research is needed to determine the reasons why a higher response to tuberculin occurs in BCG-vaccinated women and CBNAs.

Key Words: Noncontact populations; Screening; Tuberculin skin test

In 1909, von Pirquet (1) recognized the potential value of tuberculin to detect infected persons with tuberculosis (TB). Tuberculin skin testing (TST) has been the standard method for screening subjects with latent TB infection (LTBI) since the late 1930s (2). Current standards $(3,4)$ recommend that tuberculin testing should be targeted to populations at risk of
La prévalence et les prédicteurs de la réaction positive à la tuberculine chez les sujets dépistés pour d'autres raisons que l'exploration d'un contact

HISTORIQUE : Aucune étude antérieure n'a évalué le taux de réaction positive à la tuberculine (RPT) dans des populations sans contact au sein d'une même collectivité. Ces taux sont pourtant importants pour prioriser et adopter des mesures préventives.

OBJECTIFS : Évaluer la prévalence et les prédicteurs de RPT dans les populations sans contact.

MÉTHODOLOGIE : Les auteurs ont procédé à une analyse rétrospective des résultats de la tuberculine au sein des populations sans contact dépistées en Colombie-Britannique entre 1990 et 2002.

RÉSULTATS : La prévalence de la période de RPT chez 59791 sujets dépistés s'élevait à 12,7 \% (95 \% IC 12,4 \% à 13,0 \%) à 30,4\% (95\% IC $28,2 \%$ à $32,7 \%$ ) et à 60,9 \% (95 \% IC 60,3\% à 61,6 \%) chez des nonautochtones d'origine canadienne (NAOC), des autochtones d'origine canadienne $(\mathrm{AOC})$ et des personnes d'origine étrangère (POÉ), respectivement. Après contrôle de l'âge et du sexe, les prédicteurs indépendants de RPT incluaient le vaccin contre le bacille de CalmetteGuérin (VBCG) (RRR 19,6 \%, 95 \% IC 17,9 à 21,5), le pays d'origine (AOC: RRR 2,87, 95 \% IC 2,44 à 3,37; POÉ : RRR 3,67, 95 \% IC 3,34 à $4,03)$ et les populations suivantes : les résidents des centres correctionnels (RRR 4,14, 95 \% IC 1,87 à 9,15), les résidents d'établissements de soins de longue durée et de soins généraux (RRR 1,79; 95 \% IC 1,44 à 2,23), les immigrants (RRR 1,71, 95 \% IC 1,50 à 2,04), les employés des centres de santé (RRR 1,75, 95 \% IC 1,56 à 1,88), des bénévoles (RRR 1,38, 95 \% IC $1,14$ à 1,68$)$, les sujets en santé se présentant spontanément (RRR 1,30, $95 \%$ IC 1,15 à 1,48 ) et les étudiants (RRR 1,27, 95 \% IC 1,19 à 1,35). Parmi les personnes ayant reçu le VBCB, les AOC, les POÉ et les hommes étaient moins susceptibles de réagir à la tuberculine que les NAOC et les femmes $(\mathrm{P}<0,05)$.

CONCLUSIONS : Les taux de RPT sont corrélés aux taux de la maladie selon le sexe et l'origine. La poursuite des programmes de dépistage de la tuberculine est justifiée dans les populations sans contact aux taux élevés de RPT, où une exposition inconnue à des cas actifs est la plus susceptible de se produire. Des recherches supplémentaires s'imposent pour déterminer les raisons pour lesquelles on observe une réponse plus élevée à la tuberculine chez les femmes et les NAOC ayant reçu le VBCG.

progression from LTBI to active disease. Because of a higher prevalence of latent infection (henceforth referred to as tuberculin positivity [TP]) among certain groups, the incidence of TB disease may be higher among these groups than among the general population. Screening and preventive therapy programs are important for persons in these high-risk groups, particularly 
TABLE 1

Rates of tuberculin positivity (\%) by screening reason and country of birth in British Columbia from 1990 to 2002

\begin{tabular}{|c|c|c|c|c|}
\hline Screening examination reason & $\begin{array}{c}\text { Canadian-born } \\
\text { Aboriginals, } \\
n(\%)\end{array}$ & $\begin{array}{c}\text { Canadian-born } \\
\text { non-Aboriginals, } \\
\text { n (\%) }\end{array}$ & $\begin{array}{c}\text { Foreign born, } \\
\text { n (\%) }\end{array}$ & $\begin{array}{l}\text { Total, } \\
\text { n (\%) }\end{array}$ \\
\hline Correctional centre resident & $52(76.9)$ & $222(56.8)$ & $190(88.9)$ & $464(72.2)$ \\
\hline Detoxification centre client ${ }^{*}$ & $129(38.8)$ & $1,192(10.7)$ & $179(40.2)$ & $1,500(16.6)$ \\
\hline Employment, other* & $85(36.5)$ & $2,714(12.5)$ & $1,794(62.4)$ & $4,593(32.4)$ \\
\hline Health centre employee & $91(30.8)$ & $7,546(20.1)$ & $4,722(64.2)$ & $12,359(37.0)$ \\
\hline Immigration & - & - & $1,000(66.7)$ & $1,000(66.7)$ \\
\hline Child care employee of LCCFs* & $34(32.4)$ & $3,582(8.1)$ & $1,380(44.3)$ & $4,996(18.3)$ \\
\hline Resident of LCCFs & $123(37.4)$ & $1,800(18.2)$ & $473(46.1)$ & $2,396(24.7)$ \\
\hline Native Indian survey* & $699(22.0)$ & - & - & $699(22.0)$ \\
\hline Private home care support services* & $7(42.9)$ & $893(8.5)$ & $912(68.8)$ & $1,812(39.0)$ \\
\hline Preschool/parent or volunteer* & $8(37.5)$ & $1,491(6.6)$ & $735(56.1)$ & $2,234(23.0)$ \\
\hline Public service employee* & $20(55.0)$ & $1,353(14.5)$ & $484(54.1)$ & $1,857(25.3)$ \\
\hline School board employee* & $39(30.8)$ & $4,225(8.1)$ & $1,220(39.3)$ & $5,484(15.2)$ \\
\hline Self-referral, healthy & $173(30.1)$ & $1,236(17.1)$ & $688(55.7)$ & $2,097(30.8)$ \\
\hline Student & $158(32.9)$ & $7,746(8.6)$ & $9,571(64.4)$ & $17,475(39.4)$ \\
\hline Volunteer (not preschool) & $9(22.2)$ & $482(15.1)$ & $334(66.5)$ & $825(36.0)$ \\
\hline Total & $1,627(30.4)$ & $34,482(12.7)$ & $23,682(60.9)$ & $59,791(32.31)$ \\
\hline
\end{tabular}

*Served as a reference group in the multivariable analysis in Table 6. LCCFs Long-term care and community care facilities

residents of congregate settings where the risk of transmitting Mycobacterium tuberculosis is increased (eg, people living in correctional facilities, long-term care facilities and homeless shelters). Even though these high-risk groups have been identified, no previous studies have estimated and compared the rates of tuberculin reactivity within the same community after accounting for contact history. For instance, what is the rate in health care workers without known contact history as compared with the general population, and how much higher is it compared with the rate in correctional centre residents?

There is currently little evidence on rates of TP in populations not screened as part of contact investigations. In the present study, data from a longitudinal tuberculin testing program in British Columbia were used. The objective of the study was to estimate the prevalence and predictors of TP in screened non contact populations. These estimates will help to identify those settings where transmission from 'unknown' contact with TB cases is more likely to improve active case detection programs, to identify settings where routine tuberculin testing is cost-effective, and to determine the influence of demographic variables and Bacille Calmette-Guérin (BCG) vaccination on tuberculin reactivity.

\section{METHODS}

Subjects in the present study consisted of adults (18 years of age or older) who presented to health units in British Columbia for tuberculin screening from 1990 to 2002 for reasons other than contact history. During the screening visit, information was entered into a centralized computerized database of the Tuberculosis Control Division at the British Columbia Centre for Disease Control in Vancouver, British Columbia. Information included demographics, predisposing factors for TB, BCG history, presence or absence of BCG scar, and reason for screening. Although formal evaluation of BCG vaccination started in the 1930s, variations in efficacies were noted only in the 1950 s. In the present study, there were vaccinated subjects older than 60 years of age. A review of these participants showed that some of them were vaccinated during adulthood in the 1950 s as recorded in the computer system, suggesting that BCG information from the database was reliable. Subjects were referred for screening because testing was required by some programs, including detoxification centres (includes all types of drug dependencies), immigration, provincial correctional facilities, child care employees, long-term care and community care facility (LCCF) residents older than 60 years of age who had had chest $\mathrm{x}$-ray screening, health centre employees, preschool/parents or volunteers, private home care support services, some employments not health related (eg, the Royal Canadian Mounted Police, chefs, hairdressers), students (including postsecondary students, chefs, nurses, doctors, dental assistants, renal dialysis technicians and hairdressers), school board employees (recently no longer required in British Columbia) and volunteers (at hospitals or schools). Other programs included public service employees (government or social workers), self-referred healthy individuals (ie, those who suspect they may have had remote contact with a case of TB) and periodical tuberculin surveys in Canadianborn Aboriginals (CBAs) who are considered high-risk populations. The prevalence of TP in all eligible subjects in the above-mentioned groups is shown in Table 1 .

Data collected also included TST date and reaction size. A reaction size between $0 \mathrm{~mm}$ and $9 \mathrm{~mm}$ was considered negative, and a reaction size $10 \mathrm{~mm}$ or greater was considered positive according to current Canadian TB standards (4).

Because many predisposing disorders and conditions are associated with TP, and therefore represent a potential risk for selection bias or confounding effect in specific populations (eg, foreign born [FB] or Aboriginal populations), the following groups were excluded from the analysis: subjects with a history of TB, HIV, AIDS, diabetes, alcoholism, gastrectomy, radiation therapy, gastrointestinal bypass surgery, silicosis, steroid use, 
malnutrition, weight loss, malignancy (any), renal dialysis or renal transplant, doctor referrals or self-referrals due to symptoms suggesting $\mathrm{TB}$.

Only subjects with complete demographics, a reason for screening, BCG history information and the TST (one-step TST using five tuberculin units) reaction size were included in the study.

Unadjusted and adjusted ORs of variables associated with TP were obtained. The percentage differences in TP rates between BCG-vaccinated and non-BCG-vaccinated populations were analyzed using the Kruskal-Wallis test. Statistically significant variables $(\mathrm{P}<0.05)$ were included in multivariate logistic regression models using the backward elimination procedure. The core model included demographic variables and history of BCG, then a stepwise procedure was performed adding one screening population at a time to estimate the OR for each population. All screened populations with no statistically significant effect $(\mathrm{P}>0.05)$ in the stepwise procedure were considered as the reference group. The prevalence of TP varied according to the number of skin tests provided each year (data not shown); therefore, the annual number of tuberculin tests was included in the models. Several interaction terms were added in the final model to assess for interactions among sex, origin, BCG history and reason for screening.

CBAs represented the smallest sample, and they were more likely to have missing information on BCG vaccination than CBNAs or FB, which may bias the results. Therefore, a restricted multivariable analysis excluding CBAs was performed. Also, to test the reliability of BCG history, a restricted multivariable analysis including only subjects with BCG scar information was performed.

\section{Univariate analysis}

\section{RESULTS}

A total of 59,791 adults were eligible. The rates of TP were $12.7 \%$ (95\% CI $12.4 \%$ to $13.0 \%$ ), $30.4 \%$ (95\% CI $28.2 \%$ to $32.7 \%$ ) and $60.9 \%$ (95\% CI $60.3 \%$ to $61.6 \%$ ) for Canadianborn non-Aboriginals (CBNAs), CBAs and FB, respectively, with an overall rate of $32.3 \%$ (95\% CI $31.9 \%$ to $32.6 \%$ ). The median age was 33 years (range 18 to 96 years). The rate of TP was found to increase linearly with age and to be higher in male subjects, CBAs, FB and those with a positive history of BCG vaccination (Table 2 ).

In non-BCG-vaccinated subjects, CBNAs had the lowest rates overall $(7.4 \%, 95 \% \mathrm{CI} 7.1 \%$ to $7.7 \%)$ by age groups (Table 3) and by screening populations (Table 4). In BCGvaccinated subjects, CBAs had the lowest rates in all age groups (Table 3 ) and in eight of 12 comparable screening populations (Table 5) as compared with CBNAs and FB. FB had the highest overall rates in both vaccinated $(73.0 \%, 95 \%$ CI $72.3 \%$ to $73.6 \%$ ) and nonvaccinated (25.4\% (95\% CI $24.3 \%$ to $26.5 \%$ ) subjects. The analysis by country of birth and age groups showed higher rates of TP $(\mathrm{P}<0.05)$ in the $\mathrm{BCG}$-vaccinated subjects than in the nonvaccinated subjects across most age groups, except for CBAs older than 50 years of age, and CBNAs and FB 70 years of age or older. The per cent difference of TP rates between BCG-vaccinated and non-BCGvaccinated subjects was higher in CBNAs than in CBAs by age group $(\mathrm{P}=0.006)$ and screened populations $(\mathrm{P}=0.02)$. No difference was found between CBAs and $\mathrm{FB}(\mathrm{P}=0.33)$.

Except for the 'native Indian survey' population, BCGvaccinated subjects had rates above $50 \%$ (Table 5).

\begin{tabular}{|c|c|c|c|c|c|}
\hline & $\begin{array}{c}\text { Total } \\
\text { screened, } n\end{array}$ & $\begin{array}{l}\text { Positive } \\
\text { TST }^{*}, \%\end{array}$ & OR & $95 \% \mathrm{Cl}$ & $\mathbf{P}$ \\
\hline All subjects & 59,791 & 32.3 & - & - & - \\
\hline \multicolumn{6}{|l|}{ Sex } \\
\hline Female & 42,077 & 31.7 & 1 & - & - \\
\hline Male & 17,714 & 33.8 & 1.10 & 1.06 to 1.14 & $<0.0001$ \\
\hline \multicolumn{6}{|l|}{ Age group, years } \\
\hline $18-29$ & 23,769 & 22.2 & 1 & - & - \\
\hline $30-39$ & 18,754 & 35.7 & 1.9 & 1.9 to 2.0 & $<0.0001$ \\
\hline $40-49$ & 11,657 & 43.1 & 2.6 & 2.5 to 2.8 & $<0.0001$ \\
\hline $50-59$ & 4,193 & 41.8 & 2.5 & 2.3 to 2.7 & $<0.0001$ \\
\hline $60-69$ & 1,006 & 39.9 & 2.3 & 2.0 to 2.6 & $<0.0001$ \\
\hline $70+$ & 412 & 39.1 & 2.2 & 1.8 to 2.7 & $<0.0001$ \\
\hline \multicolumn{6}{|l|}{ Country of birth } \\
\hline \multicolumn{6}{|l|}{ Canadian born } \\
\hline Non-Aboriginals & Is 34,482 & 12.7 & 1 & - & - \\
\hline Aboriginals & 1,627 & 30.4 & 3.0 & 2.7 to 3.3 & $<0.0001$ \\
\hline Foreign born & 23,682 & 60.9 & 10.7 & 10.3 to 11.1 & $<0.0001$ \\
\hline \multicolumn{6}{|c|}{ Bacille Calmette-Guérin history } \\
\hline Negative & 38,417 & 10.6 & 1 & - & - \\
\hline Positive & 21,374 & 71.2 & 20.8 & 19.9 to 21.7 & $<0.0001$ \\
\hline
\end{tabular}

Subjects had a median age of 33 years (age range 18 to 96 years). *TST that produced a reaction size of $10 \mathrm{~mm}$ or greater was considered positive

\section{Multivariable analysis}

The core model showed the following variables were associated with skin test positivity: male sex (OR 1.23, 95\% CI 1.12 to 1.35 ), age (OR $3.9,95 \%$ CI 3.6 to 4.2 ), CBA (OR 2.87, 95\% CI 2.44 to 3.37), FB (OR 3.67, 95\% CI 3.34 to 4.03 ) and BCG vaccination (OR 19.6, 95\% CI 17.9 to 21.5). Populations marked with an asterisk in Table 1 were not associated with TP in the multivariable analysis, and therefore, were considered the reference group. Populations associated with TP included correctional centre residents (OR 4.14, 95\% CI 1.87 to 9.15), residents of LCCFs (OR $1.79,95 \%$ CI 1.44 to 2.23 ), immigrants (OR $1.75,95 \%$ CI 1.50 to 2.04), health centre employees (OR 1.71, 95\% CI 1.56 to 1.88 ), volunteers (OR $1.38,95 \%$ CI 1.14 to 1.68 ), self-referred healthy subjects (OR $1.30,95 \%$ CI 1.15 to 1.48 ) and students (OR 1.27, 95\% CI 1.19 to 1.35 ). TP was associated with the number of skin tests administered (OR 1.75, $95 \%$ CI 1.67 to 1.84 ) (Table 6). The interaction terms showed that vaccinated CBAs (OR 0.23, 95\% CI 0.18 to 0.30 ) and vaccinated $\mathrm{FB}$ (OR $0.50,95 \% \mathrm{CI} 0.45$ to 0.56 ) were less likely to react than vaccinated CBNAs. FB health centre employees (OR 0.85, 95\% CI 0.76 to 0.96), FB LCCF residents (OR $0.49,95 \% \mathrm{CI} 0.38$ to 0.63 ) and vaccinated male subjects (OR 0.73, 95\% CI 0.64 to 0.82 ) were less likely to react than their counterparts. FB men (OR 1.22, 95\% CI 1.08 to 1.38 ) and male residents from correctional centres (OR 3.49, 95\% CI 1.51 to 8.04 ) or from LCCFs (OR 1.30, $95 \%$ CI 1.02 to 1.67 ) were more likely to react than their female counterparts. The model excluding CBAs and the model including only subjects with BCG scar information showed the same trend and similar estimates when compared 
TABLE 3

Rates of tuberculin positivity (\%) by Bacille Calmette-Guérin (BCG) vaccination history, age group and country of birth

\begin{tabular}{|c|c|c|c|c|c|c|c|}
\hline \multirow[b]{2}{*}{$\begin{array}{l}\text { Age group, } \\
\text { years }\end{array}$} & \multicolumn{3}{|c|}{ Negative history of BCG } & \multicolumn{3}{|c|}{ Positive history of BCG } & \multirow[b]{2}{*}{$\begin{array}{l}\text { Total, } \\
\text { n (\%) }\end{array}$} \\
\hline & $\begin{array}{c}\text { Canadian-born } \\
\text { Aboriginals, } \\
\text { n (\%) }\end{array}$ & $\begin{array}{c}\text { Canadian-born } \\
\text { non-Aboriginals, } \\
n(\%)\end{array}$ & $\begin{array}{c}\text { Foreign born, } \\
\text { n (\%) }\end{array}$ & $\begin{array}{l}\text { Canadian-born } \\
\text { Aboriginals, } \\
\text { n (\%) }\end{array}$ & $\begin{array}{c}\text { Canadian-born } \\
\text { non-Aboriginals, } \\
\text { n (\%) }\end{array}$ & $\begin{array}{c}\text { Foreign born, } \\
\text { n (\%) }\end{array}$ & \\
\hline $30-39$ & $274(16.4)$ & $9,246(7.3)$ & $1,647(24.2)$ & $174(55.7)$ & $1,029(66.4)$ & $6,384(75.2)$ & $18,754(35.7)$ \\
\hline $40-49$ & $200(32.0)$ & $4,934(12.2)$ & $1,310(29.8)$ & $128(59.4)$ & $1,111(70.5)$ & $3,974(78.2)$ & $11,657(43.1)$ \\
\hline $50-59$ & $98^{*}(42.9)$ & $1,890(17.8)$ & $643(40.0)$ & $41(43.9)$ & $468(66.2)$ & $1,053(74.8)$ & $4,193(41.8)$ \\
\hline $70+$ & $34^{*}(38.2)$ & $198^{*}(36.4)$ & $156^{*}(39.7)$ & $1(0.0)$ & $9(66.7)$ & $14(57.1)$ & $412(39.1)$ \\
\hline Total & $1,095(21.0)$ & $31,313(7.4)$ & $6,009(25.4)$ & $532(49.8)$ & $3,169(64.9)$ & $17,673(73.0)$ & $59,791(32.3)$ \\
\hline
\end{tabular}

Except for those values marked with an asterisk, there was a statistically significant difference $(P<0.05)$ between $B C G$-vaccinated and non-BCG-vaccinated rates for the specific country of birth and age group using $\chi^{2}$ or Fisher's exact test

\section{TABLE 4}

Rates of tuberculin positivity $(\%)$ in subjects with a negative history of Bacille Calmette-Guérin vaccination in British Columbia from 1990 to 2002

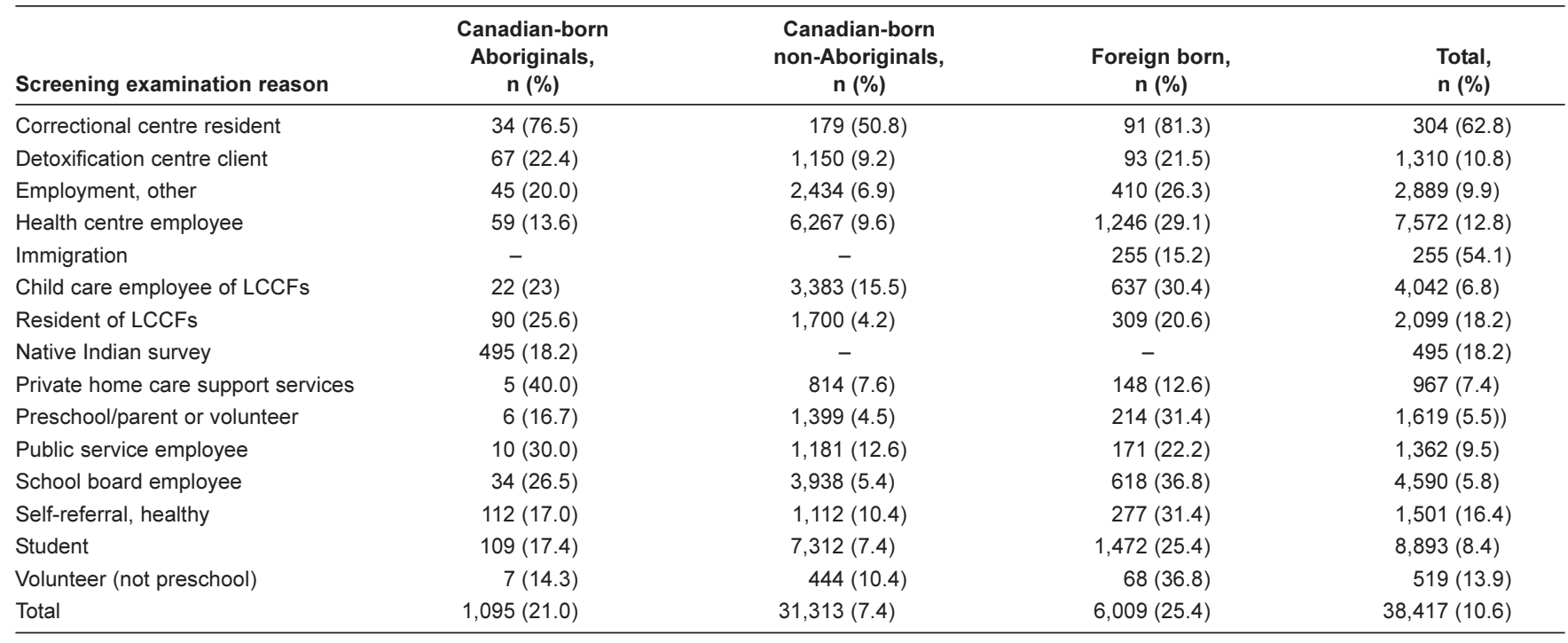

LCCFs Long-term care and community care facilities

\section{TABLE 5}

Rates of tuberculin positivity (\%) in subjects with a positive history of Bacille Calmette-Guérin vaccination in British Columbia from 1990 to 2002

\begin{tabular}{|c|c|c|c|c|}
\hline Screening examination reason & $\begin{array}{c}\text { Canadian-born } \\
\text { Aboriginals, } \\
\text { n (\%) }\end{array}$ & $\begin{array}{c}\text { Canadian-born } \\
\text { non-Aboriginals, } \\
\text { n (\%) }\end{array}$ & $\begin{array}{c}\text { Foreign born, } \\
\mathrm{n}(\%)\end{array}$ & $\begin{array}{l}\text { Total, } \\
\text { n (\%) }\end{array}$ \\
\hline Correctional centre resident & $18(77.8)$ & $43(81.4)$ & $99(96.0)$ & $160(90.0)$ \\
\hline Detoxification centre client & $62(56.5)$ & $42(50.0)$ & $86(60.5)$ & $190(56.8)$ \\
\hline Employment, other & $40(55.0)$ & $280(60.4)$ & $1,384(73.0)$ & $1,704(70.5)$ \\
\hline Health centre employee & $32(62.5)$ & $1,279(71.7)$ & $3,476(76.8)$ & $4,787(75.3)$ \\
\hline Immigration & - & - & $745(71.0)$ & $745(71.0)$ \\
\hline Child care employee of LCCFs & $12(50.0$ & $199(63.0)$ & $743(69.3)$ & $954(66.9)$ \\
\hline Resident of LCCFs & $33(70)$ & $100(53.2)$ & $164(75.6)$ & $297(70.7)$ \\
\hline Native Indian survey & $204(31.4)$ & - & - & $204(31.4)$ \\
\hline Private home care support services & $2(50.0)$ & $79(62)$ & $764(77)$ & $845(75.0)$ \\
\hline Preschool/parent or volunteer & $2(100.0)$ & $92(56.8)$ & $521(70.6)$ & $615(68.9)$ \\
\hline Public service employee & $10(80.0)$ & $172(57.3)$ & $313(71.9)$ & $495(68.5)$ \\
\hline School board employee & $5(60.0)$ & $287(62.7)$ & $602(66.8)$ & $894(63.5)$ \\
\hline Self-referral, healthy & $61(54.1)$ & $124(71.1)$ & $411(72.0)$ & $596(67.1)$ \\
\hline Student & $49(67.3)$ & $434(62.7)$ & $8,099(72.0)$ & $8,582(71.5)$ \\
\hline Volunteer (not preschool) & $2(50.0)$ & $38(64.9)$ & $266(74.1)$ & $306(73.5)$ \\
\hline Total & $532(49.8)$ & $3,169(64.9)$ & $17,673(73.0)$ & $21,374(71.2)$ \\
\hline
\end{tabular}


TABLE 6

Multivariable analysis of associated predictors of tuberculin positivity in British Columbia from 1990 to 2002

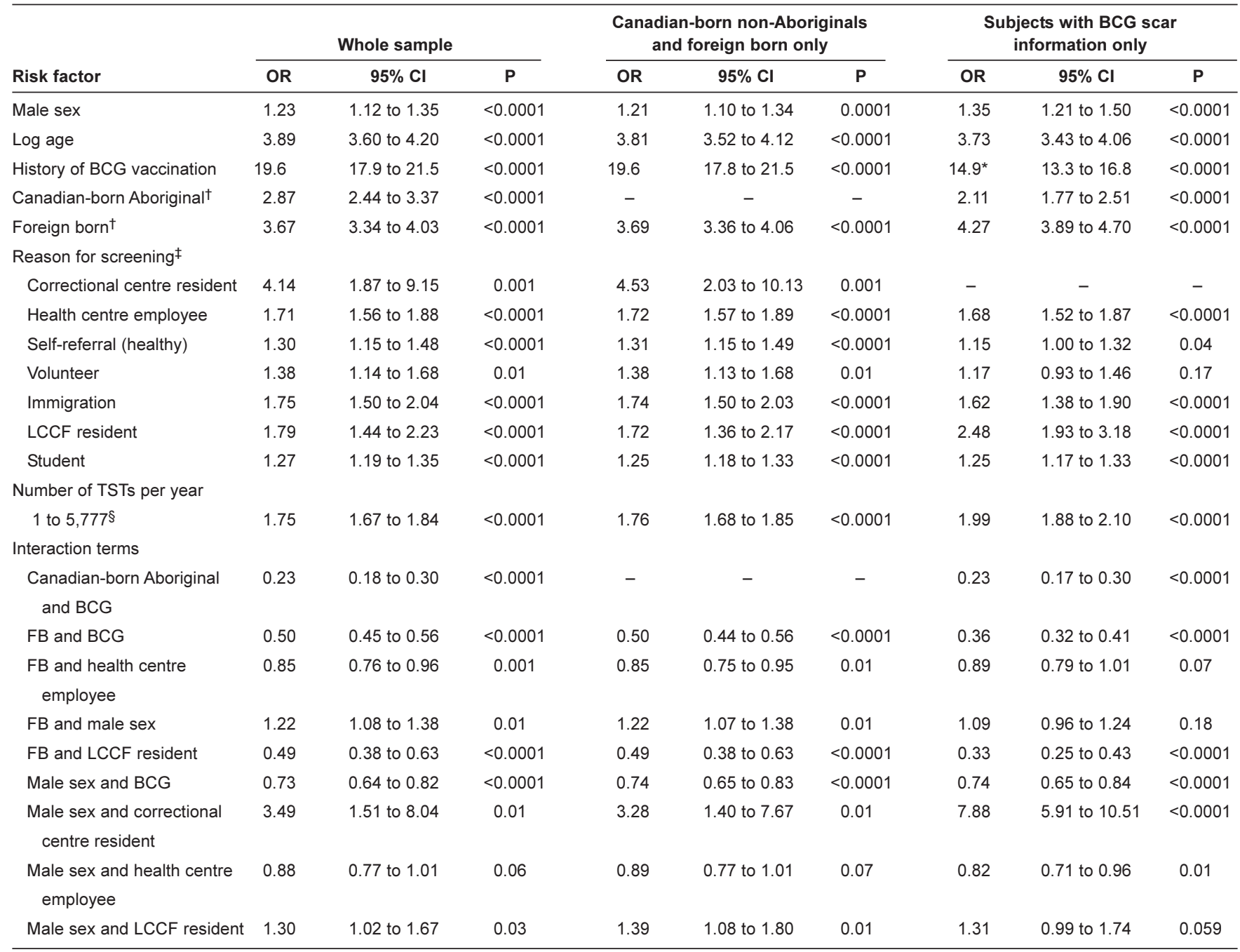

${ }^{*}$ OR for people with Bacille Calmette-Guérin (BCG) scar; ${ }^{\dagger}$ Canadian-born non-Aboriginals served as the reference group; ${ }^{*}$ Reasons for screening not displayed in this table served as the reference group (shown in Table 1); \&Years with more than 5777 tuberculin skin tests (TSTs) (the median) served as the reference group. FB Foreign born; LCCF Long-term care and community care facility

with the whole sample. Two exceptions were the 'correctional centre residents' and 'volunteers' in the BCG scar model, which showed no statistically significant effect (Table 6).

\section{DISCUSSION}

To our knowledge, this is the first study to compare the prevalence and predictors of TP in noncontact populations within the same community. The results may be useful as a reference for comparison with other jurisdictions within Canada. The prevalence of TP by country of birth showed the same trend as the rates of disease in Canada (5), with the lowest in CBNAs $(12.7 \%)$ followed by CBAs $(30.4 \%)$ and the highest in FB $(60.9 \%)$. As expected, lower rates were found in nonvaccinated subjects; CBNAs had the lowest rates of TP $(7.4 \%$, Table 4), which is probably the closest estimate of TP prevalence in 'unexposed' CBNAs living in British Columbia. This rate may also reflect exposure to nontuberculous mycobacterial infection. The rates of TP in nonvaccinated household contacts in British Columbia have been estimated to be $27 \%, 51 \%$ and $63.2 \%$ for CBNAs, CBAs and FB, respectively (unpublished data), which are 3.6, 2.4 and 2.4 times higher than the estimates in noncontact nonvaccinated subjects found in the present study, respectively.

We also found that age, male sex, country of origin (CBAs, FB) and BCG vaccination were independent predictors of TP. Additionally, we found that vaccinated CBNAs and female subjects react more to tuberculin.

Tuberculin reactivity rates increased linearly with age, which is presumably explained by the cumulative exposure to unknown cases of TB or to nontuberculous mycobacteria. It is known that men have higher susceptibility to TB disease than women (6). Our findings also suggest that men are more susceptible to TP than women.

These demographic results are consistent with other studies $(7,8)$. Our analysis also suggests that men, particularly male FB and male residents at LCCF or correctional centres, are more likely to react to tuberculin than women from those settings. However, interestingly, vaccinated male subjects were less likely to have a positive tuberculin than vaccinated female subjects.

BCG-vaccinated subjects were approximately 20 times more likely to have a positive reaction and had higher rates than non-BCG-vaccinated subjects across all age groups. This 
is consistent with a large study from Africa (7) that indicates that the relationship between age and tuberculin reactivity has the same trend in BCG-vaccinated subjects regardless of disease prevalence.

The present study demonstrated that the impact of BCG vaccination on TST was strongly affected by country of origin. CBAs and FB showed lower rates in BCG-vaccinated subjects than CBNAs, and this was consistent across all age groups and screened populations. These results indicate that vaccinated populations with high risk of disease (ie, CBAs, FB and male subjects) react less to tuberculin than low-risk vaccinated populations (CBNAs, females subjects). This is analogous to a recent study (9) in infants from West Africa where the mortality rate ratios were lower in children with a BCG scar and a positive tuberculin test. The BCG response was more strongly related to survival for girls than for boys.

In our study, it is likely that FB subjects were vaccinated with various strains, which might explain their lower rates than CBNAs. However, it is also likely that CBAs received the same strain as CBNAs, and that Canadian-born women and men received the same strain. Therefore, differences in rates are unlikely to be due to differences in vaccine strains. The reasons for a higher TST reactivity in vaccinated CBNAs may include an increased immunological memory to tuberculin antigens, and genetic or diet differences. Diet habits, such as protein deficiencies, have been associated with reduced TST positivity $(10,11)$. The possibility of anergy, as seen in the immuncompromised, is unlikely because they were excluded from our study. The restricted analysis of subjects with BCG scar information and the analysis excluding CBAs from the multivariable analysis showed similar estimates, confirming that the small number of subjects in some CBA populations did not bias the results and that BCG history information is reliable.

The risk of TP was approximately four times higher in correctional facilities, suggesting that the setting with higher exposure to unknown $\mathrm{TB}$ cases was responsible for the increased risk, especially in a low-incidence country such as Canada. The high risk of TP in inmates may be explained by higher risk factors for TB (12), the lack of screening programs to detect individuals with new TST conversions (13) and difficulties in identifying, evaluating, and treating TB cases and contacts in these settings $(14,15)$. Other populations with high TP rates included residents of LCCFs, immigrants, health centre employees, volunteers, self-referred healthy subjects and students. Preventive measures in these groups should be reinforced, and the continuation of the tuberculin screening program is warranted.

The present study has some limitations. Underreporting of negative TST results at correctional facilities may have occurred, which could have overestimated the rates of TP in these settings. Also, some volunteers and students were screened because they volunteered or studied at health-related settings, including hospitals (eg, medical or nursing students), and they could presumably be more exposed to active cases and have higher risk of infection. Specific volunteer or area of study information was not available, so we were unable to separate volunteers or students at health-related facilities from students or volunteers at other settings. Further research is needed to estimate the rates in volunteers and students not exposed to health-related settings.

Even though the rates of infection were relatively low in detoxification centre clients, we were unable to separate intravenous drug users, who are considered a high-risk population (3), from abusers of other substances with the risk of selection bias, which would underestimate the rates. The results in volunteers, students and detoxification centre clients should therefore be interpreted with caution.

False-positive tuberculin tests occur in subjects who have been infected with Mycobacterium species other than $M$ tuberculosis because they share the same antigens $(16,17)$. A substantial proportion of subjects with a positive tuberculin test in the present study may have yielded false-positive results and may explain an unknown portion of positive skin tests.

Some other limitations inherent to tuberculin studies include timing, method, experience of readers, and terminal digit preferences or rounding (18). Continuous training of readers and routine use of calipers are recommended in all screening programs. Despite these limitations, the tuberculin test remains the standard screening method for detection of LTBI. The new interferon gamma release assay tests (QuantiFERON - TB Gold, Cellestis Ltd, Australia) and T-SPOT.TB (Oxford Immunotec, United Kingdom) are not affected by BCG vaccination nor by certain nontuberculous mycobacteria, and they are therefore attractive alternatives to the TST. However, some limitations of these tests include their high cost, the need for venepuncture and laboratory facilities. Even though these tests are more specific than TST for LTBI detection, these limitations will likely restrict their use as a screening tool in noncontact high-risk populations.

\section{CONCLUSIONS}

Our findings suggest that the tuberculin screening program should be discontinued for preschool parents or volunteers, private home care support services, child care employees, school board employees, employment purposes and general native Indian surveys. The results may be useful in identifying background TST positive rates during contact tracing. They also call for reassessment of the tuberculin screening program, which should be focused on and prioritized to populations with high rates of TP, including correctional facilities, residents of selected LCCFs, immigrants, health centre employees, volunteers, self-referred subjects and students groups where unknown exposure to active cases is more likely to occur. Further research is needed to determine the reasons for and implications of higher TP in vaccinated CBNA subjects and women.

ACKNOWLEDGEMENTS: We thank the clerks, nurses and outreach workers who facilitated the collection of epidemiological data. We also thank Paul Vial for data extraction and management of the final database.

\section{REFERENCES}

1. von Pirquet C. Frequency of tuberculosis in childhood. J Am Med Assoc 1909;52:675-8.

2. Seibert FB, Glenn JT. Tuberculin purified protein derivative: Preparation and analysis of a large quantity for standard. Am Rev Tuberc 1941;44:9-25.

3. American Thoracic Society, Centers for Disease Control and Prevention, Infectious Diseases of America. Targeted Tuberculin Testing and Treatment of Latent Tuberculosis Infection. MMWR Recomm Rep 2000;49:1-51.

4. Long R, ed. Canadian Tuberculosis Standards, 5th edn. Ottawa: Canadian Lung Association and Health Canada, 2000.

5. Public Health Agency of Canada. Tuberculosis in Canada 2002. $<$ http://www.phac-aspc.gc.ca/publicat/tbcan02/> (Version current at May 6, 2008) 
6. World Health Organization. Tuberculosis and gender. $<$ http://www.who.int/tb/challenges/gender/page_1/en/index.html> (Version current at May 6, 2008).

7. Fine PE, Bruce J, Ponnighaus JM, Nkhosa P, Harawa A, Vynnycky E. Tuberculin sensitivity: Conversions and reversions in a rural African population. Int J Tuberc Lung Dis 1999;3:962-75.

8. Lienhardt C, Fielding K, Sillah J, et al. Risk factors for tuberculosis infection in sub-Saharan Africa: A contact study in The Gambia. Am J Respir Crit Care Med 2003;168:448-55.

9. Roth A, Sodemann M, Jensen H, et al. Tuberculin reaction, BCG scar, and lower female mortality. Epidemiology 2006;17:562-8.

10. Sinha DP, Bang FB. Protein and calorie malnutrition, cell-mediated immunity, and B.C.G. vaccination in children from rural West Bengal. Lancet 1976;2:531-4.

11. Kardjito T, Donosepoetro M, Grange JM. The Mantoux test in tuberculosis: Correlations between the diameters of the dermal responses and the serum protein levels. Tubercle 1981;62:31-5.

12. Glaser JB, Greifinger RB. Correctional health care: A public health opportunity. Ann Intern Med 1993;118:139-45.
13. Pelletier AR, DiFerdinando GT Jr, Greenberg AJ, et al. Tuberculosis in a correctional facility. Arch Intern Med 1993; 153:2692-5.

14. McLaughlin SI, Spradling P, Drociuk D, Ridzon R, Pozsik CJ, Onorato I. Extensive transmission of Mycobacterium tuberculosis among congregated, HIV-infected prison inmates in South Carolina, United States. Int J Tuberc Lung Dis 2003; 7:665-72.

15. Centers for Disease Control and Prevention. Tuberculosis outbreaks in prison housing units for HIV-infected inmates - California, 1995-1996. MMWR Morb Mortal Wkly Rep 1999;48:79-82.

16. Daniel TM, Janicki BW. Mycobacterial antigens: A review of their isolation, chemistry, and immunological properties. Microbiol Rev 1978;42:84-113.

17. Harboe M. Antigens of PPD, old tuberculin, and autoclaved Mycobacterium bovis BCG studied by crossed immunoelectrophoresis. Am Rev Respir Dis 1981;124:80-7.

18. Bass J Jr. The tuberculin test. In: Reichman LD, Herschfield ES, eds. Tuberculosis: A comprehensive international approach. New York: Marcel Dekker, 1993:139-48. 


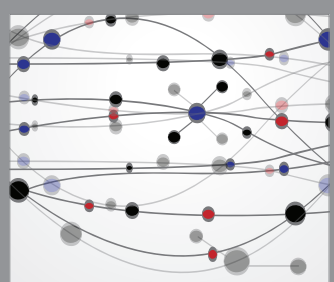

The Scientific World Journal
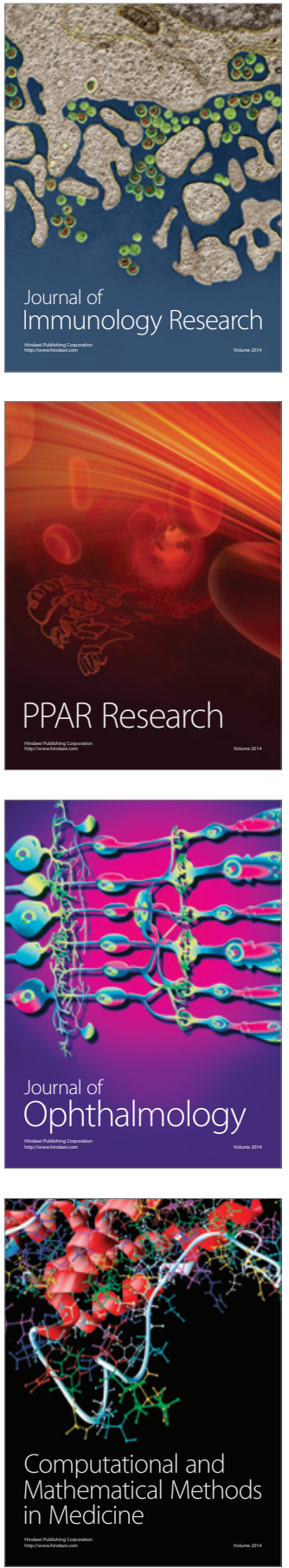

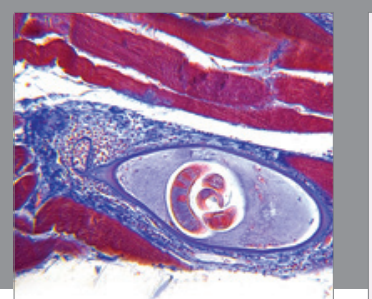

Gastroenterology Research and Practice

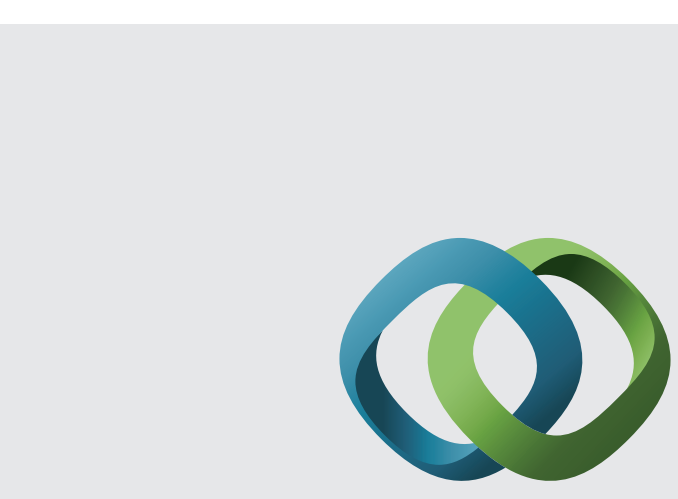

\section{Hindawi}

Submit your manuscripts at

http://www.hindawi.com
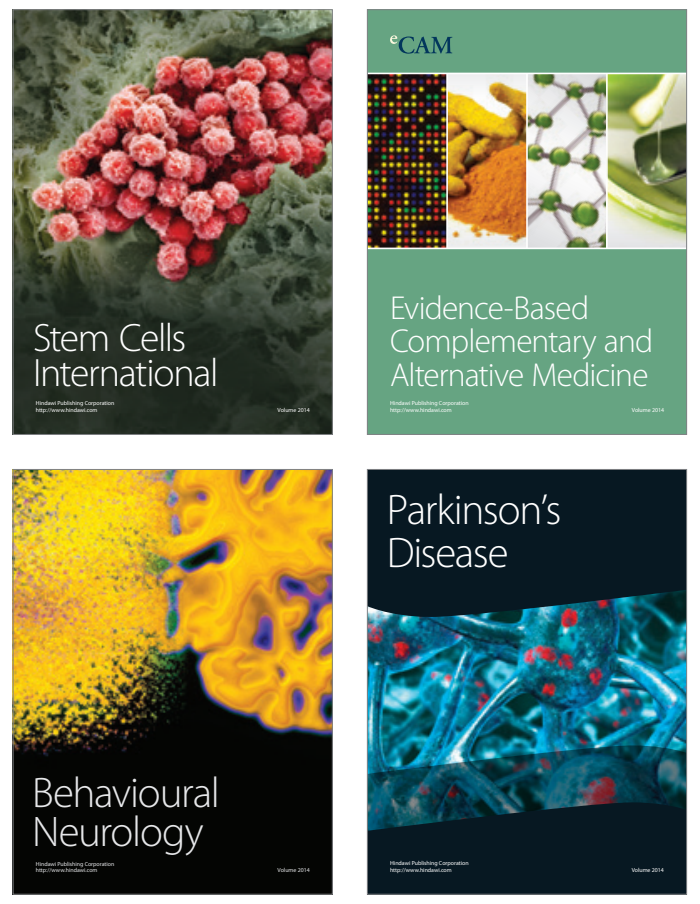
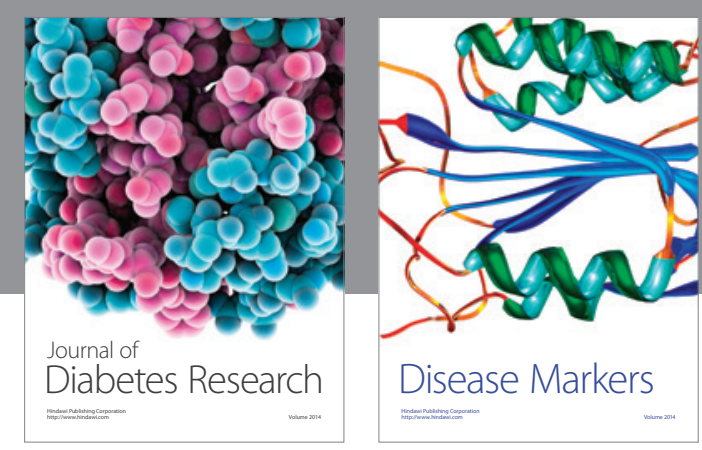

Disease Markers
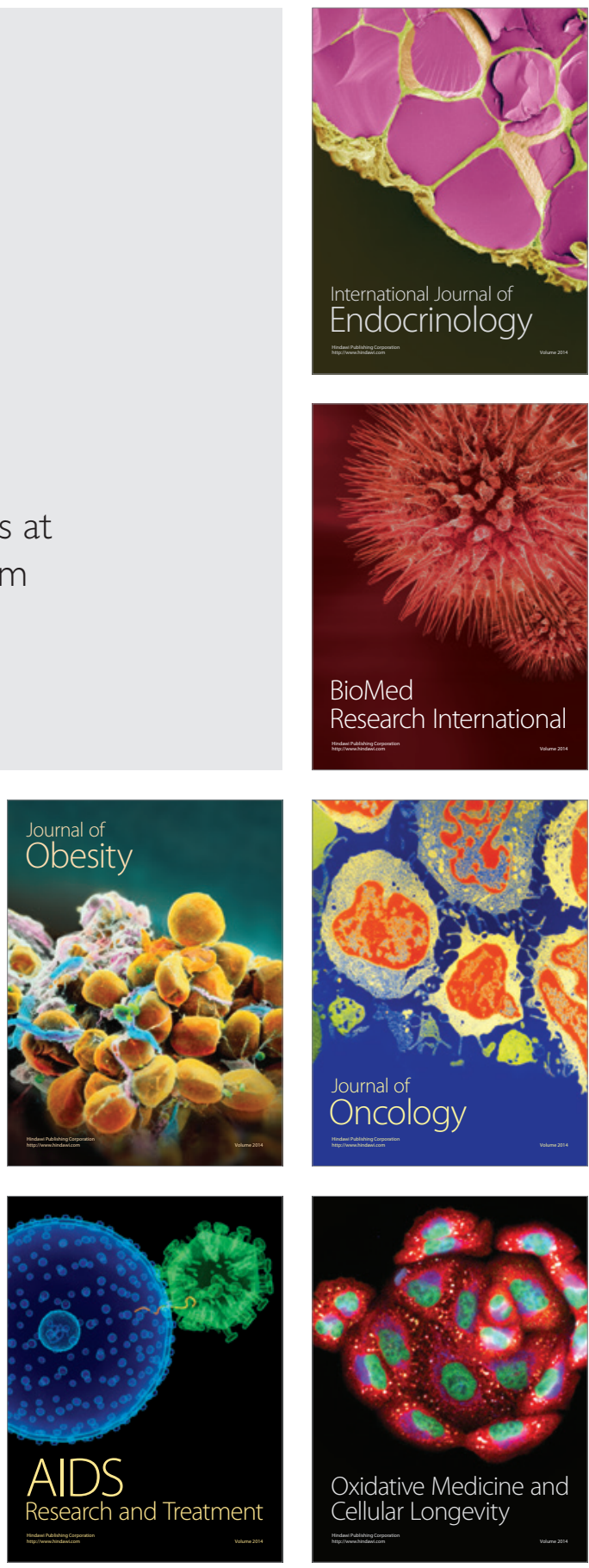